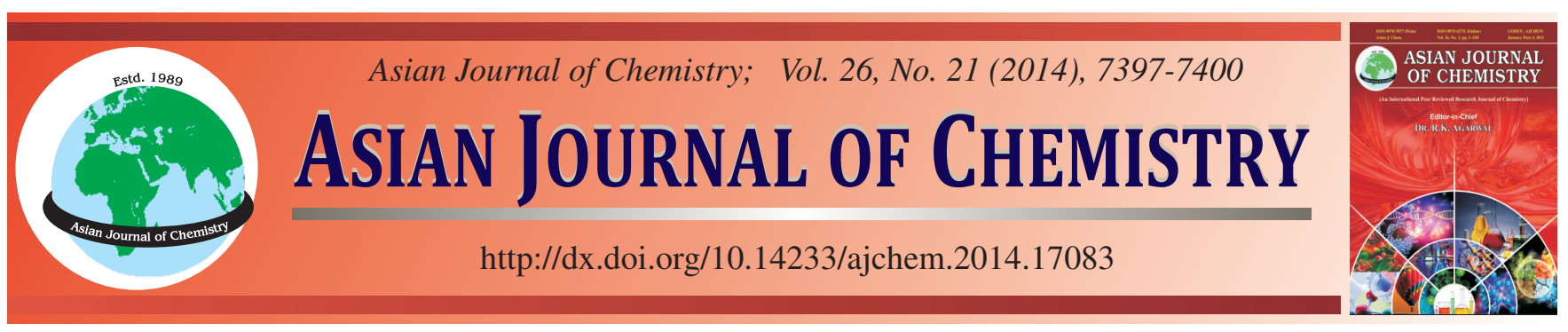

\title{
Synthesis, Crystal Structure and DFT Studies of $N$-[4-(Heptyloxy)phenyl]-4-methylpyrimidin-2-amine
}

\author{
LeI-Ting Wu, NA-Bo Sun ${ }^{*}$ and FAnG-Yue He
}

${ }^{1}$ College of Biology and Environmental Engineering, Zhejiang Shuren University, Hangzhou 310015, Zhejiang, P.R. China

*Corresponding author: E-mail: nabosun@gmail.com

Received: 20 January 2014;

Accepted: 21 February 2014;

Published online: 30 September 2014;

AJC-16146

The compound $N$-[4-(heptyloxy)phenyl]-4-methylpyrimidin-2-amine with the molecular formula $\mathrm{C}_{18} \mathrm{H}_{25} \mathrm{~N}_{3} \mathrm{O}$ was synthesized and
recrystallized from $\mathrm{CH}_{3} \mathrm{OH}$. The compound was characterized by ${ }^{1} \mathrm{H}$ NMR, MS, HRMS and X-ray diffraction. The compound crystallized
in the monoclinic space group P2(1)/c with a $=9.426(2), \mathrm{b}=14.434(3), \mathrm{c}=12.884(3) \AA, \alpha=90, \beta=93.779(3), \gamma=90^{\circ}, \mathrm{V}=1749.2$
$(6) \AA^{3}, \mathrm{Z}=4$ and $\mathrm{R}=0.0402$ for 1798 observed reflections with $\mathrm{I}>2 \sigma(\mathrm{I})$. Theoretical calculation of the title compound was carried out
with $\mathrm{B} 3 \mathrm{LYP} / 6-31 \mathrm{G}(\mathrm{d}, \mathrm{p})$. The full geometry optimization was carried out using 6-31G (d, p) basis set and the frontier orbital energy. The
optimized geometric bond lengths and bond angles obtained by using DFT(B3LYP) show the best agreement with the experimental data.

Keywords: Pyrimidine, Synthesis, Crystal structure, Theoretical calculation.

ᄂ - - - - - - - - - - - - - - - - - - - - - - - - -

\section{INTRODUCTION}

In recent years, heterocyclic compounds are used as key scaffolds in the biological active compounds, especially in medicines or pesticides ${ }^{1-8}$. It is reported that pyrimidines exhibited diversity biological activities, such as antileishmanial ${ }^{9}$, antitumor agents ${ }^{10}$, antioxidant ${ }^{11}$, antiplasmodium falciparum agents $^{12}$, KDR inhibitors ${ }^{13}$, dihydroorotate dehydrogenase inhibitors ${ }^{14}$, herbicidal activities ${ }^{15}$, etc. Some of pyrimidine derivatives had been developed to commercial agrochemicals and medicines, such as sulfometuron-methyl, bensulfuronmethyl, pyrazosulfuron-ethyl, nicosulfuron, azimsulfuron, amidosulfuron, flumetsulam, florasulam, 5-FU, etc. The phenoxy group always used in the drug discovery due to its excellent activity, such as antibacterial ${ }^{16}$, antifungal ${ }^{17}$, herbicidal $^{18}$, anti-HIV ${ }^{19}$, antioxidant ${ }^{20}$, anticancer activity ${ }^{21}$, etc.

In view of these facts mentioned above and also as a part of our work on the synthesis of bioactive lead compounds for drug discover ${ }^{22,23}$, the title compounds i.e., $N$-[4-(heptyloxy)phenyl]-4-methylpyrimidin-2-amine synthesized and characterized by ${ }^{1} \mathrm{H}$ NMR, MS and HRMS. The single crystal structure of the title compound was determined by X-ray diffraction. Theoretical calculation of the title compound was also carried out with B3LYP/6-31G (d, p).

\section{EXPERIMENTAL}

Melting points were determined using an X-4 apparatus and uncorrected. ${ }^{1} \mathrm{H}$ NMR spectra were measured on a Bruker
AV-400 instrument using TMS as an internal standard and $\mathrm{CDCl}_{3}$ as the solvent. Mass spectra were recorded on a Thermo Finnigan LCQ Advantage LC/mass detector instrument. Elemental analysis was performed on a Vario EL elemental analyzer. All the reagents are of analytical grade or freshly prepared before use.

Therotical calculations: According to the above crystal structure, a crystal unit was selected as the initial structure, while DFT-B3LYP/6-31G (d, p) methods in Gaussian 03 package ${ }^{24}$ were used to optimize the structure of the title compound. Vibration analysis showed that the optimized structures were in accordance with the minimum points on the potential energy surfaces, which means no virtual frequencies, proving that the obtained optimized structures were stable. All the convergent precisions were the system default values and all the calculations were carried out on the home computer.

Synthesis: The title compound was synthesized according to the route shown in Scheme-I and the yields were not optimized. The pyrimidine $\mathbf{4}$ was synthesized according to the references.

To a solution of 4-nitrophenol (15 mmol), $\mathrm{K}_{2} \mathrm{CO}_{3}(2.96 \mathrm{~g}$, $0.02 \mathrm{~mol})$ and $\mathrm{KI}(0.2 \mathrm{~g})$ in EtOH $(15 \mathrm{~mL}), 1$-bromoheptane (16 mmol) was added. The resulting mixture was stirred at refulxing for $7 \mathrm{~h}$. After cooling, the solvent was evaprated. The pure product $\mathbf{2}$ was obtained in good yields. Russety liquid, yield $44 \%$. Then the mixture of compound $2(70 \mathrm{~mL})$, $\mathrm{NH}_{2} \mathrm{NH}_{2} \cdot \mathrm{H}_{2} \mathrm{O}(75 \mathrm{~mL}, 80 \%)$ and Raney nickel $(0.5 \mathrm{~g})$ was refluxing in methanol, the mixture was filtrated after refluxing $1 \mathrm{~h}$, the solvent was evaporated to afford white solid. The 


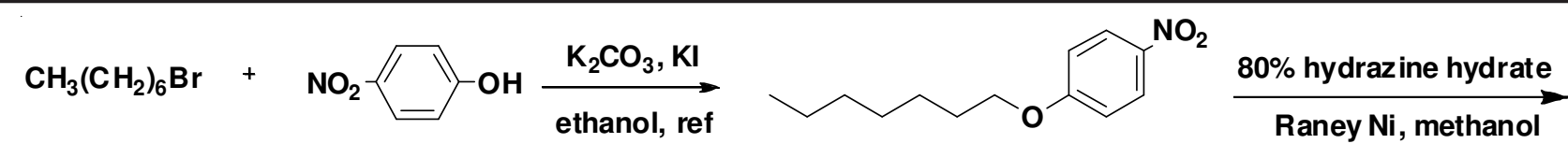<smiles>CCCCCCCOc1ccc(N)cc1</smiles>

3<smiles>Cc1ccnc(N)n1</smiles>
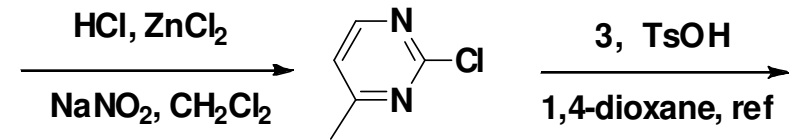

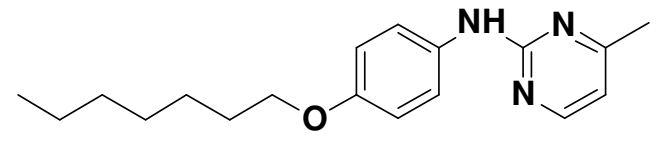

5

Scheme-I: Synthetic route of title compound

compound 3 was recrystallization in methanol. Yield, $88 \%$; m.p., 32-33 ${ }^{\circ} \mathrm{C} .{ }^{1} \mathrm{H}$ NMR (400 MHz, $\left.\mathrm{CDCl}_{3}\right), 6.73$ (d, $J=8.7$ $\mathrm{Hz}, 2 \mathrm{H}, \mathrm{Ph}-\mathrm{H}), 6.63$ (d, $J=8.7 \mathrm{~Hz}, 2 \mathrm{H}, \mathrm{Ph}-\mathrm{H}), 3.87$ (t, $J=6.6$ $\left.\mathrm{Hz}, 2 \mathrm{H}, \mathrm{OCH}_{2}\right), 3.24$ (br, $2 \mathrm{H}, \mathrm{NH}_{2}$ ), 1.68-1.78 (m, 2H, $\mathrm{CH}_{2}$ ), 1.28-1.44 (m, 10H, $\left.\left(\mathrm{CH}_{2}\right)_{5}\right), 0.88\left(\mathrm{t}, \mathrm{J}=6.9 \mathrm{~Hz}, 3 \mathrm{H}, \mathrm{CH}_{3}\right)$. To a solution of compound $3(3.6 \mathrm{mmol})$ and 4 (3 mmol) in 1,4dioxane $(20 \mathrm{~mL})$, 4-methylbenzenesulfonic acid (0.46 g, 2.4 $\mathrm{mmol}$ ) was added. The mixture was refluxed for $5 \mathrm{~h}$. After the reaction was completed, the 1,4-dioxane was evaporated, the residue was washed with saturated $\mathrm{NaHCO}_{3}$ solution and extracted several times with ethyl acetate. The combined organic phases were washed with brine, dried over $\mathrm{Na}_{2} \mathrm{SO}_{4}$ and evaporated. The remainder was purified by chromatography on silica gel using petroleum ether $\left(60-90^{\circ} \mathrm{C}\right)$ and ethyl acetate as the eluent to afford the compound $\mathbf{5}$. Wihte crystal, yield $61.5 \%$, m.p. $65-66{ }^{\circ} \mathrm{C},{ }^{1} \mathrm{H}$ NMR $\left(\mathrm{CDCl}_{3}, 300 \mathrm{MHz}\right), \delta$ : $8.23(\mathrm{~d}, J=5.1 \mathrm{~Hz}, 1 \mathrm{H}$, pyrimidine-H), $7.48(\mathrm{~d}, J=8.7 \mathrm{~Hz}$, 2H, Ph-H), 6.95 (bs, 1H, NH), 6.87 (d, J=8.7 Hz, 2H, Ph-H), $6.54(\mathrm{~d}, J=5.1 \mathrm{~Hz}, 1 \mathrm{H}$, pyrimidine-H), $3.94(\mathrm{t}, J=6.6 \mathrm{~Hz}$, $\left.2 \mathrm{H}, \mathrm{OCH}_{2}\right), 2.39\left(\mathrm{~s}, 3 \mathrm{H}\right.$, pyrimidine- $\left.\mathrm{CH}_{3}\right), 1.72-1.81(\mathrm{~m}, 2 \mathrm{H}$, $\left.\mathrm{CH}_{2}\right), 1.3-1.45\left(\mathrm{~m}, 8 \mathrm{H},\left(\mathrm{CH}_{2}\right)_{4}\right), 0.89\left(\mathrm{t}, J=6.9 \mathrm{~Hz}, 3 \mathrm{H}, \mathrm{CH}_{3}\right)$. MS (ESI), $m / z: 301[\mathrm{M}+\mathrm{H}]^{+}$. Elemental anal. (\%), calcd. C, 66.36; H, 4.95; N, 12.90; found: C, 66.20; H, 5.10; N, 12.79.

Structure determination: The cube-shaped single crystal of the title compound was obtained by recrystallization from EtOH. The crystal with dimensions of $0.34 \mathrm{~mm} \times 0.20 \mathrm{~mm} \times$ $0.26 \mathrm{~mm}$ was mounted on a Rigaku Saturn diffractometer with a graphite-monochromated $\operatorname{MoK}_{\alpha}$ radiation $(\lambda=0.71073 \AA)$ by using a Phi scan modes at 294 (2) $\mathrm{K}$ in the range of $2.12^{\circ}=$ $\theta=25.02^{\circ}$. A total of 8941 reflections were collected, of which 3082 were independent $($ Rint $=0.0402)$ and 1798 were observed with $I>2 \sigma(I)$. The calculations were performed with SHELXS97 program $^{25}$ and the empirical absorption corrections were applied to all intensity data. The non-hydrogen atoms were refined anisotropically. The hydrogen atoms were determined with theoretical calculations and refined isotropically. The final full-matrix least squares refinement gave $\mathrm{R}=0.0525$ and $\mathrm{wR}$ $=0.1307\left(\mathrm{w}=1 /\left[\sigma^{2}\left(\mathrm{~F}_{\mathrm{o}}^{2}\right)+(0.0664 \mathrm{P})^{2}+0.5602 \mathrm{P}\right]\right.$ where $\mathrm{P}=$
$\left.\left(\mathrm{F}_{\mathrm{o}}^{2}+2 \mathrm{~F}_{\mathrm{c}}{ }^{2}\right) / 3\right), \mathrm{S}=1.02,(\Delta / \sigma)_{\max }=0.002, \Delta \rho_{\max }=0.190$ and

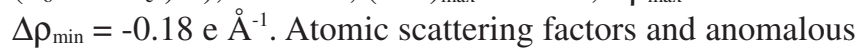
dispersion corrections were taken from International Table for $\mathrm{X}$-Ray crystallography ${ }^{26}$. A summary of the key crystallgraphic information were given in Table-1.

\begin{tabular}{|c|c|}
\hline \multicolumn{2}{|c|}{$\begin{array}{c}\text { TABLE-1 } \\
\text { CRYSTAL STRUCTURE AND DATA } \\
\text { REFINEMENT PARAMETERS }\end{array}$} \\
\hline Empirical formula & $\mathrm{C}_{18} \mathrm{H}_{25} \mathrm{~N}_{3} \mathrm{O}$ \\
\hline Formula weight & 299.41 \\
\hline Crystal system/space group & Monoclinic, $\mathrm{P} 2(1) / \mathrm{c}$ \\
\hline 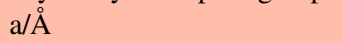 & $9.426(2)$ \\
\hline $\mathrm{b} / \AA ̊$ & $14.434(3)$ \\
\hline $\mathrm{c} / \AA ̊ \AA$ & $12.884(3)$ \\
\hline$\alpha^{\circ}$ & 90 \\
\hline$\beta /^{\circ}$ & $93.779(3)$ \\
\hline$\gamma /{ }^{\circ}$ & 90 \\
\hline $\mathrm{V} / \AA^{3}$ & $1749.2(6)$ \\
\hline $\mathrm{Z}$ & 4 \\
\hline$D_{\text {calc. }}\left(\mathrm{g} / \mathrm{cm}^{3}\right)$ & 1.137 \\
\hline$\mu\left(\mathrm{mm}^{-1}\right)$ & 0.07 \\
\hline Crystal size (mm) & $0.34 \times 0.30 \times 0.26$ \\
\hline Color/Shape & Colorless/cube \\
\hline Temp. (K) & $294(2)$ \\
\hline Theta range for collection & 2.12 to $25.02^{\circ}$ \\
\hline Reflections collected & 8941 \\
\hline Independent reflections & 3082 \\
\hline Data/restraints/parameters & $3082 / 108 / 253$ \\
\hline Goodness of fit on $\mathrm{F}^{2}$ & 1.021 \\
\hline Final $R$ indices $[\mathrm{I}>2 \sigma(\mathrm{I})]$ & $\mathrm{R} 1=0.0525, \mathrm{wR} 2=0.1307$ \\
\hline $\mathrm{R}$ indices (all data) & $\mathrm{R} 1=0.1006, \mathrm{wR} 2=0.1609$ \\
\hline Largest difference peak/hole & 0.189 and -0.180 \\
\hline
\end{tabular}

\section{RESULTS AND DISCUSSION}

The synthesis procedures for title compound were shown in Scheme-I. The 1-(heptyloxy)-4-nitrobenzene was synthesized easily from the starting materials 4-nitrophenol and 1-bromoheptane with mild condition. The 1-(heptyloxy)-4nitrobenzene can be reduced by Raney nickel to regard 4- 
(heptyloxy)aniline. We also use $\mathrm{Fe} / \mathrm{HCl}, \mathrm{SnCl}_{2}$ to reduce, but the yield and purity are low. Due to the environmental protect, the $\mathrm{H}_{2}, \mathrm{Pd} / \mathrm{C}$ system is tried to reduce the nitro group. The reduction process is clean and easy. In the process of title compound, some conditions were tried, but the reaction can not work, such as different base $\left(\mathrm{K}_{2} \mathrm{CO}_{3}, \mathrm{NaOH}, \mathrm{Et}_{3} \mathrm{~N}, \mathrm{NaH}\right.$, pyridine $)$, different solvent (EtOH, THF, acetone) and difference reaction temperature. Surprisingly, it is reported that acid can synthesize $\mathrm{N}$-phenylpyrimidin-2-amine. So the title compound was synthesized under the catalyst 4-methylbenzenesulfonic acid.

Spectra: The proton magnetic resonance spectra of the title compound have been recorded in $\mathrm{CDCl}_{3}$. The $\mathrm{NH}$ proton of chemical shift is at $\delta 6.95$ as a singlet. The signal of $\mathrm{OCH}_{2}$ protons was observed at $\delta 3.94 \mathrm{ppm}$ as a singlet. The chemical shifts at 8.23 and $6.54 \mathrm{ppm}$ are the proton of pyrimidine. The chemical shifts of methyl group of pyrimidine at $2.39 \mathrm{ppm}$. Also the phenyl ring protons are divide into two double peak at 7.48 and $6.87 \mathrm{ppm}$. The title compound of mass spectra is molecular ion peak. The ESI-MS spectrum showed that the $\mathrm{m} / \mathrm{z}$ of molecular ion was 301, according with its molecular formula $\mathrm{C}_{18} \mathrm{H}_{25} \mathrm{~N}_{3} \mathrm{O}$. The elemental analysis result is according with the calculated results.

Crystal structure: The selected bond lengths and bond angles are shown in Tables 2 and 3. The molecular structure of the title compound is shown in Fig. 1. The molecular packing of the molecule is shown in Fig. 2.

\begin{tabular}{|c|c|c|}
\hline \multicolumn{3}{|c|}{$\begin{array}{c}\text { TABLE-2 } \\
\text { SELECTED BOND LENGTHS [̊] AND THEROTICAL } \\
\text { CALCULATIONS FOR THE TITLE COMPOUND }\end{array}$} \\
\hline Bond & X-ray Crystal & DFT \\
\hline $\mathrm{O}(1)-\mathrm{C}(9)$ & $1.375(3)$ & 1.36853 \\
\hline $\mathrm{O}(1)-\mathrm{C}(12)$ & $1.428(3)$ & 1.42463 \\
\hline $\mathrm{N}(1)-\mathrm{C}(4)$ & $1.331(3)$ & 1.32788 \\
\hline $\mathrm{N}(1)-\mathrm{C}(5)$ & $1.352(3)$ & 1.35641 \\
\hline $\mathrm{N}(2)-\mathrm{C}(5)$ & $1.360(3)$ & 1.36986 \\
\hline $\mathrm{N}(2)-\mathrm{C}(6)$ & $1.417(3)$ & 1.40682 \\
\hline $\mathrm{C}(1)-\mathrm{C}(2)$ & $1.497(4)$ & 1.50544 \\
\hline $\mathrm{C}(2)-\mathrm{N}(3)$ & $1.343(3)$ & 1.34274 \\
\hline $\mathrm{C}(2)-\mathrm{C}(3)$ & $1.387(4)$ & 1.39539 \\
\hline $\mathrm{C}(5)-\mathrm{N}(3)$ & $1.342(3)$ & 1.34185 \\
\hline $\mathrm{C}(6)-\mathrm{C}(7)$ & $1.381(3)$ & 1.39979 \\
\hline \multicolumn{3}{|c|}{$\begin{array}{c}\text { TABLE- } 3 \\
\text { SELECTED BOND ANGLES }\left[^{\circ}\right] \text { AND THEROTICAL } \\
\text { CALCULATIONS FOR THE TITLE COMPOUND }\end{array}$} \\
\hline Angle & X-ray crystal & DFT \\
\hline $\mathrm{C}(9)-\mathrm{O}(1)-\mathrm{C}(12)$ & $117.9(2)$ & 118.50206 \\
\hline $\mathrm{C}(4)-\mathrm{N}(1)-\mathrm{C}(5)$ & $114.9(2)$ & 115.50920 \\
\hline $\mathrm{C}(5)-\mathrm{N}(2)-\mathrm{C}(6)$ & $127.7(2)$ & 132.51403 \\
\hline $\mathrm{N}(3)-\mathrm{C}(2)-\mathrm{C}(3)$ & $121.2(3)$ & 121.54381 \\
\hline $\mathrm{N}(3)-\mathrm{C}(2)-\mathrm{C}(1)$ & $115.8(3)$ & 116.19481 \\
\hline $\mathrm{C}(3)-\mathrm{C}(2)-\mathrm{C}(1)$ & $123.0(3)$ & 122.26138 \\
\hline $\mathrm{C}(4)-\mathrm{C}(3)-\mathrm{C}(2)$ & $117.2(3)$ & 116.56386 \\
\hline $\mathrm{N}(1)-\mathrm{C}(4)-\mathrm{C}(3)$ & $123.9(3)$ & 123.26726 \\
\hline $\mathrm{N}(3)-\mathrm{C}(5)-\mathrm{N}(1)$ & $126.2(2)$ & 126.26536 \\
\hline $\mathrm{N}(3)-\mathrm{C}(5)-\mathrm{N}(2)$ & $118.8(2)$ & 120.38789 \\
\hline $\mathrm{N}(1)-\mathrm{C}(5)-\mathrm{N}(2)$ & $115.0(2)$ & 113.34675 \\
\hline $\mathrm{C}(5)-\mathrm{N}(3)-\mathrm{C}(2)$ & $116.6(2)$ & 115.50920 \\
\hline$C(7)-C(6)-C(11)$ & $117.9(2)$ & 118.41705 \\
\hline $\mathrm{C}(7)-\mathrm{C}(6)-\mathrm{N}(2)$ & $118.2(2)$ & 116.78079 \\
\hline $\mathrm{C}(11)-\mathrm{C}(6)-\mathrm{N}(2)$ & $123.7(2)$ & 124.80208 \\
\hline $\mathrm{C}(6)-\mathrm{C}(7)-\mathrm{C}(8)$ & $121.9(2)$ & 120.39639 \\
\hline
\end{tabular}

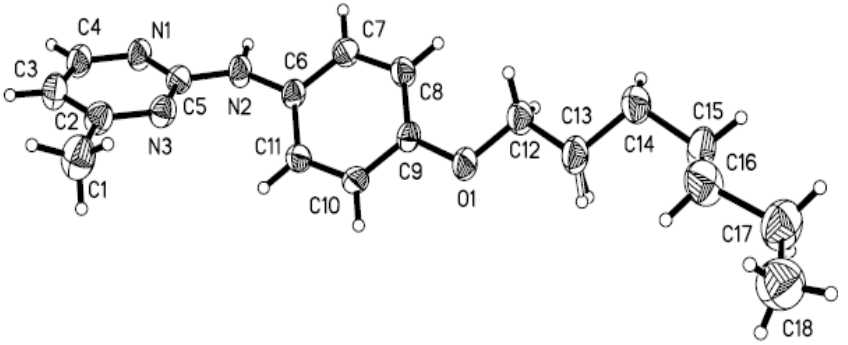

Fig. 1. Molecular structure of the title compound

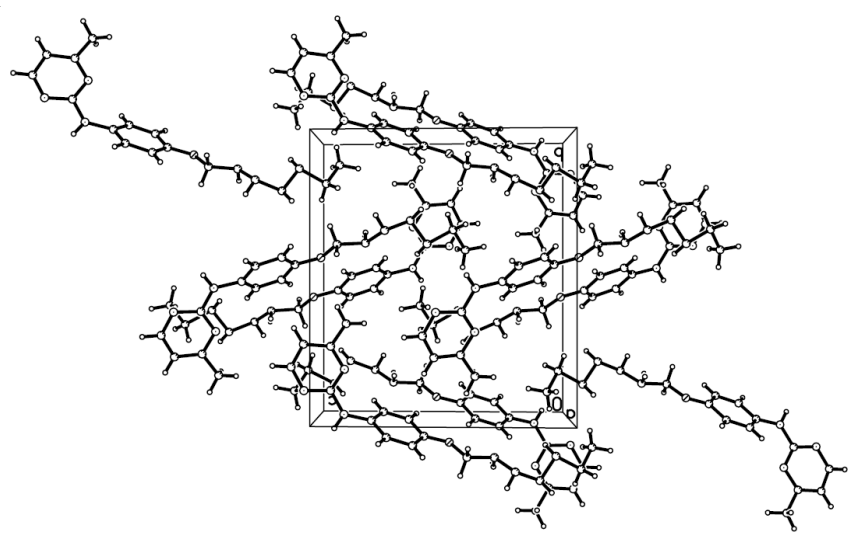

Fig. 2. Molecular packing of the molecule

The title compound consists of pyrimidine ring and benzene ring according to X-ray single-crystal structure determination. Generally, the average bond lengths and bond angles of ring system (phenyl and pyrimidine) are normal ranges ${ }^{15,27-29}$. The C5-N2 bond [1.360 (3) $\mathrm{A}]$ is shorter than the general C-N bond length of $1.47 \AA$, but it is similar with the bond (N1-C5(1.352 (3) ̊), N3-C5(1.342 (3) ̊), C6-C7 (1.381 (3) ̊), C6-C11(1.387 (3) $\AA$ ). It is indicated that the $\mathrm{C}-\mathrm{N}-\mathrm{C}$ form a $\mathrm{p}-\pi$ conjugated with pyrimidine and benzene ring. The bond angle of $\mathrm{C} 11-$ N1-C14 is $127.7(2)^{\circ}$. In Tables 2 and 3, it can be easily seen that DFT results have good coherence with the crystal diffraction.

As shown in Fig. 1, the pyrimidine ring $(\mathrm{C} 2, \mathrm{C} 3, \mathrm{C} 4, \mathrm{~N} 1$, $\mathrm{C} 5, \mathrm{~N} 2)$ and phenyl ring $(\mathrm{C} 6, \mathrm{C} 7, \mathrm{C} 8, \mathrm{C} 9, \mathrm{C} 10, \mathrm{C} 11)$ is fairly planar with plane equation $8.356 x+4.792 y+-4.897 z=0.1978$ $(3.762 x+12.046 y+-5.220 z=-0.7245)$ and the largest deviation from the least squares plane is $0.0039 \mathrm{~nm}(0.0019 \mathrm{~nm})$. Also, it is nearly that the pyrimidine ring is nearly vertical with phenyl ring $(\mathrm{C} 6, \mathrm{C} 7, \mathrm{C} 8, \mathrm{C} 9, \mathrm{C} 10, \mathrm{C} 11)$ with the dihedral angle of $41.1^{\circ}$.

Molecular total energies and frontier orbital energy analysis: Molecular total energy and frontier orbital energy levels are listed in Table-4. Energy gap between HOMO and LUMO calculated by B3LYP.

\section{TABLE-4}

TOTAL ENERGY AND FRONTIER ORBITAL ENERGY

\begin{tabular}{cc}
\hline & DFT \\
\hline $\mathrm{E}_{\text {total }} /$ Hartree $^{\mathrm{b}}$ & -940.516 \\
$\mathrm{E}_{\text {HOMO }} /$ Hartree & -0.184 \\
$\mathrm{E}_{\text {LUMO }} /$ Hartree & -0.029 \\
$\Delta \mathrm{E}^{\mathrm{a}} /$ Hartree & 0.155 \\
\hline
\end{tabular}

${ }^{\mathrm{a}} \Delta \mathrm{E}=\mathrm{E}_{\text {LUмо }}-\mathrm{E}_{\text {Hомо }} ;{ }^{\mathrm{b}} 1$ Hartree $=4.35974417 \times 10^{-18} \mathrm{~J}=27.2113845 \mathrm{ev}$ 
According to the frontier molecular orbital theory, HOMO and LUMO are the most important factors that affect the bioactivity. HOMO has the priority to provide electrons, while LUMO can accept electrons firstly. Thus study on the frontier orbital energy can provide useful information about the biological mechanism. From the Fig. 3, the geometry of the frame of $\mathbf{5}$ is hardly influenced by the introduction of either pyrimidine ring or benzene ring. The HOMO of the title compound is mainly located on the aromatic ring, while the LUMO of the title compound is located on the aromatic ring and methyl group. The fact that the title compound has strong affinity suggests the importance of the frontier molecular orbital in the $p-\pi$ stacking or hydrophobic interactions.

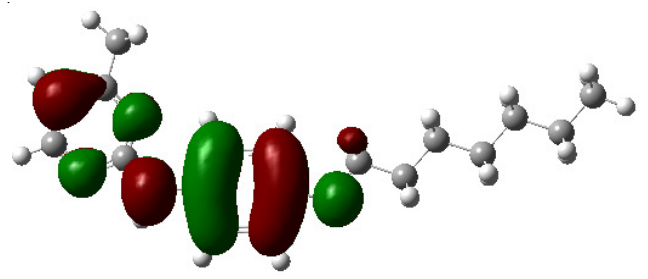

LUMO Plot (First excited state
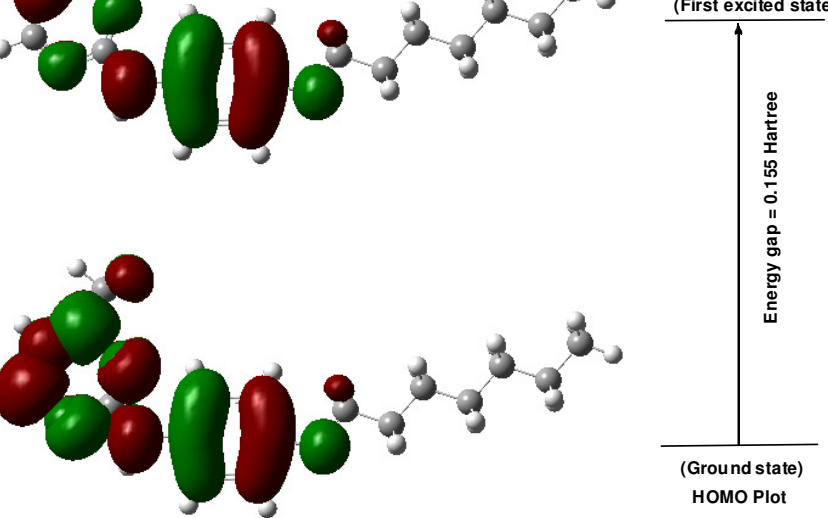

Fig. 3. Frontier molecular orbitals of 5

\section{ACKNOWLEDGEMENTS}

The authors thank Dr. Wu Jing to determine the compound. This work is supported by National Natural Science Foundation of Zhejiang Province (No. LQ13B020003), Applied Chemistry Foundation of Zhejiang Shuren University (SH2013S04, YH2013G02).

\section{REFERENCES}

1. W. Ke, N.B. Sun and H.K. Wu, Asian J. Chem., 25, 8708 (2013).

2. X.H. Liu, W.G. Zhao, B.L. Wang and Z.M. Li, Res. Chem. Intermed., 38, 1999 (2012).

3. J.Q. Weng, L. Wang and X.H. Liu, J. Chem. Soc. Pak., 34, 1248 (2012).

4. W. Ke, N.B. Sun and H.K. Wu, Asian J. Chem., 25, 8723 (2013).

5. X.H. Liu, J.Q. Weng and C.X. Tan, J. Chem., Article ID 306361 (2013).

6. N.N. Su, Y. Li, S.J. Yu, X. Zhang, X.H. Liu and W.G. Zhao, Res. Chem. Intermed., 39, 759 (2013).
7. C.X. Tan, J.Q. Weng, Z.X. Liu, X.H. Liu and W.G. Zhao, Phosphorus Sulfur Silicon Relat. Elem., 187, 990 (2012).

8. W. Ke, N.B. Sun and H.K. Wu, Asian J. Chem., 25, 8715 (2013).

9. M.H. Bukhari, H.L. Siddiqui, C.M. Ashraf and T. Hussain, J. Chem. Soc. Pak., 33, 720 (2011)

10. M.G. Badrey and S.M. Gomha, Molecules, 17, 11538 (2012).

11. M.M. Youssef and M.A. Amin, Molecules, 17, 9652 (2012).

12. N. Boechat, L.C.S. Pinheiro, T.S. Silva, A.C.C. Aguiar, A.S. Carvalho, M.M. Bastos, C.C.P. Costa, S. Pinheiro, A.C. Pinto, J.S. Mendonça, K.D.B. Dutra, A.L. Valverde, O.A. Santos-Filho, I.P. Ceravolo and A.U. Krettli, Molecules, 17, 8285 (2012).

13. X.Y. Wu, W.H. Chen, S.G. Wu, Y.X. Tian and J.J. Zhang, Int. J. Mol. Sci., 13, 2387 (2012).

14. S.L. Li, M.Y. He and H.G. Du, Int. J. Mol. Sci., 12, 2982 (2011).

15. P.Q. Chen, C.X. Tan, J.Q. Weng and X.H. Liu, Asian J. Chem., 24, 2808 (2012).

16. X. Ma, W. Zhou and R. Brun, Bioorg. Med. Chem. Lett., 19, 986 (2009).

17. N.-B. Sun, Y.-X. Shi, X.-H. Liu, Y. Ma, C.-X. Tan, J.-Q. Weng, J.-Z. Jin and B.-J. Li, Int. J. Mol. Sci., 14, 21741 (2013).

18. X.H. Liu, L. Pan, Y. Ma, J.Q. Weng, C.X. Tan, Y.H. Li, Y.X. Shi, B.J. Li, Z.M. Li and Y.G. Zhang, Chem. Biol. Drug Des., 78, 689 (2011).

19. A. Nuhrich, M. Varache-Lembège, C. Jarry and G. Devaux, Eur. J. Med. Chem., 27, 857 (1992).

20. K.S. Roser, P.S. Brookes, A.P. Wojtovich, L.P. Olson, J. Shojaie, R.L. Parton and M.W. Anders, Bioorg. Med. Chem., 18, 1441 (2010).

21. R.K. Anchoori, M.S.Q. Kortenhorst, M. Hidalgo, T. Sarkar, G. Hallur, R. Bai, P.J.V. Diest, E. Hamel and S.R. Khan, J. Med. Chem., 51, 5953 (2008).

22. N.B. Sun, J.Y. Tong and H.K. Wu, Chin. J. Org. Chem., 33, 101 (2013).

23. J.Y. Tong, Y.X. Shi, X.H. Liu, N.B. Sun and B.J. Li, Chin. J. Org. Chem., 32, 2373 (2012).

24. M.J. Frisch, G.W. Trucks, H.B. Schlegel, G.E. Scuseria, M.A. Robb, J.R. Cheeseman and J.A. Jr, Montgomery, T. Vreven, K.N. Kudin, J.C. Burant, J.M. Millam, S.S. Iyengar, J. Tomasi, V. Barone, B. Mennucci, M. Cossi, G. Scalmani, N. Rega, G.A. Petersson, H. Nakatsuji, M. Hada, M. Ehara, K. Toyota, R. Fukuda, J. Hasegawa, M. Ishida, T. Nakajima, Y. Honda, O. Kitao, H. Nakai, M. Klene, X. Li, J.E. Knox, H.P. Hratchian, J.B. Cross, C. Adamo, J. Jaramillo, R. Gomperts, R.E. Stratmann, O. Yazyev, A.J. Austin, R. Cammi, C. Pomelli, J.W. Ochterski, P.Y. Ayala, K. Morokuma, G.A. Voth, P. Salvador, J.J. Dannenberg, V.G. Zakrzewski, S. Dapprich, A.D. Daniels, M.C. Strain, O. Farkas, D.K. Malick, A.D. Rabuck, K. Raghavachari, J.B. Foresman, J.V. Ortiz, Q. Cui, A.G. Baboul, S. Clifford, J. Cioslowski, B.B. Stefanov, G. Liu, A. Liashenko, P. Piskorz, I. Komaromi, R.L. Martin, D.J. Fox, T. Keith, M.A. AlLaham, C.Y. Peng, A. Nanayakkara, M. Challacombe, P.M.W. Gill, B. Johnson, W. Chen, M.W. Wong, C. Gonzalez, J.A. Pople, Gaussian 03, Revision C. 01, Gaussian, Inc., Wallingford CT, (2004).

25. G.M. Sheldrick, SHELXS97 and SHELXL97, University of Göttingen, Germany, (1997)

26. A.J. Wilson, International Table for X-ray Crystallograghy, Vol C, Kluwer Academic Publisher, Dordrecht, Tables 6.1.1.4 (500) and 4.2.6.8, 219, (1992).

27. H.J. Liu, J.Q. Weng, C.X. Tan and X.H. Liu, Acta Crystallogr., E67, o1940 (2011).

28. Y.L. Xue, Y.G. Zhang and X.H. Liu, Asian J. Chem., 24, 5087 (2012).

29. X.H. Liu, C.-X. Tan, J.-Q. Weng and H.-J. Liu, Acta Crystallogr., E68, o493 (2012). 